\title{
Preparing Higher Education Leaders: A Conceptual, Strategic, and Operational Approach
}

\author{
Ralph A. Gigliotti \\ Assistant Director, Center for Organizational Development \& Leadership \\ Doctoral Candidate and Part-Time Lecturer, Communication \\ Rutgers University \\ Brent D. Ruben \\ Executive Director of the Center for Organizational Development and Leadership \\ Distinguished Professor, Communication \\ Rutgers University
}

\begin{abstract}
Leadership is widely accepted as a critical factor to the success, mediocrity, or failure of an organization (Collins, 2001; March \& Weil, 2005; Northouse, 2015). This is no less the case in higher education, where the impact of leaders and leadership is critical to academic and administrative effectiveness. This is especially true given the myriad challenges facing higher education, including significant decreases in public support, conflicting opinions about the purpose of higher education, opportunities presented by new technologies for teaching and learning, and a rapidly shifting and competitive global economy. Given this tumultuous environment, there is a pressing need for increased attention to leadership development within colleges and universities (Bolman \& Gallos, 2011; Buller, 2014; Gmelch \& Buller, 2015; Ruben, 2004; Ruben, De Lisi, \& Gigliotti, 2017).

This article begins with a review of the current higher education landscape, focusing particularly on a number of leadership challenges that are most germane to colleges and universities across the globe. The article continues with a review of the existing literature on higher education leadership needs and competencies, and current approaches to providing leadership education. We then present a case study of a leadership development framework and a portfolio of programs designed to address knowledge- and skill-development needs within higher education that has been developed by the Center for Organizational Development and Leadership at Rutgers University. The framework has led to the creation of a portfolio of programs for academic and administrative leaders in varying stages of development that will be described in the article. It is our hope that this comprehensive approach to leadership education - an approach that is conceptual, strategic, and operational - will serve as a useful model for scholars and practitioners across higher education. The key concepts raised in this article may prove useful for those involved in the design and delivery of leadership education programs for higher education, healthcare, and other large institutions with multiple audiences, needs, and goals. Furthermore, the differentiation of the conceptual, strategic, and operational dimensions may be a useful framework for those interested in the study and practice of leadership education.
\end{abstract}




\section{A Challenging Landscape}

Colleges and universities both nationally and internationally face an array of challenges that often threaten the existence of these institutions. As Altbach and Davis (1999) note in the introduction to their report for the Institute of International Education, "While academic systems function in a national environment, the challenges play themselves out on a global scale" (p. 3). The authors go on to suggest that the shared historical roots and common contemporary challenges call for increased international dialogue as a way of best addressing these leadership challenges. Issues related to the privatization of higher education, the "crisis" of the academic profession, demands for greater accountability, challenges to student access, and the need for more agile and innovative change in the face of a rapidly shifting and competitive global economy are not limited to U.S. colleges and universities; rather, these challenges are relevant to all institutions of higher education and they demand global leadership attention. In addition to these challenges, there exists a growing expectation for leaders in higher education to have an understanding of the needs, goals, and perceptions of the many diverse stakeholders who maintain an interest in colleges and universities.

These leadership challenges are interdependent by nature, and they often have a cascading impact on the leadership functions at all levels within higher education institutions. For example, the emphasis on outcomes measurement, changes in student demographics and preferences, demands for greater transparency in decision making, requirements for new technologies, and decreased public funding have a rippling effect on all aspects of higher education. The leadership issues to be addressed, including the erosion of goodwill and public support, coupled with the organizational, financial, technological, and ideological dilemmas facing colleges and universities, are multi-faceted and complex, transcend academic and administrative roles, and involve both faculty and staff. There may have been a time when being a leader in one's discipline or technical area was sufficient preparation for academic or administrative leadership within a college or university. Those times are gone. Today's leader must have a broad understanding of the higher education landscape, an array of organizational and leadership concepts and tools, and the professional and personal competencies necessary to translate these capabilities into practice on a routine basis (Ruben, De Lisi, \& Gigliotti, 2017; Gigliotti, under review).

\section{Higher Education Leadership}

There is no shortage of ways to think about leadership (Bass, 2008; Grint, 2000; Northouse, 2015; Ruben, 2012). In our view, leadership is best viewed from a broad perspective as a process of social influence - a process that occurs through communication (Ruben, De Lisi, \& Gigliotti, 2017; Ruben \& Gigliotti, 2016). This perspective highlights the fact that leadership efforts and leadership outcomes may be planned or unplanned, formal or informal, may involve verbal and nonverbal messaging, and depend as much on followership dynamics as much as leader activity (Ruben \& Gigliotti, 2016). By foregrounding the role of communication theory in understanding the dynamics of leadership and leadership influence (Barge \& Fairhurst, 2008; Fairhurst, 2007; Fairhurst \& Connaughton, 2014a, 2014b; Fairhurst \& Sarr, 1996; Witherspoon, 1997), effective leadership in higher education is seen as involving the ability to navigate the many challenges, cultures, and stakeholders involved in higher education and engaging 
colleagues to collaborate in these activities (Ruben, De Lisi, \& Gigliotti, 2017). Communication, thus, serves as an orientation, a world view, a way of understanding leadership that focuses more broadly on the process of social influence (Ruben \& Gigliotti, 2016). This orientation extends also into the domain of leadership education and development, particularly in the context of higher education.

The need for leadership development initiatives has long been recognized in the military and business, with some estimating that American corporations spending nearly $\$ 160$ billion annually on training and development programs (Association for Talent Development, 2015). Considering the scope and scale of challenges facing leaders in higher education, there is a perceived scarcity of formal education programs available to those with academic or administrative leadership responsibilities (Gigliotti, forthcoming).

As discussed elsewhere (Ruben, De Lisi, \& Gigliotti, 2017), these leadership development efforts have been slower to reach the education industry, and colleges and universities in particular, due in part to the perception that subject matter expertise and experience are the primary ingredients necessary to provide effective leadership in higher education. We are currently witnessing a change in attitude on this topic as these traditions change, and as an increasing number of colleges and universities identify the need to focus greater attention on leadership development. As noted by Gmelch and Buller (2015), "Through academic leadership programs, institutions benefit from making the most effective use of this resource, building connections across campus, promoting purposeful leadership diversity, tapping hidden talent, retaining campus talent, expanding people's potential, and ensuring institutional renewal, effectiveness, and dedication" (p. 198).

In their research on the topic, Gmelch, Hopkins, and Damico (2011) found three ingredients of an effective leadership development program that represent the needs and expectations for college and university administrators. These ingredients include habits of mind (an understanding of concepts), habits of practice (a demonstration of skills), and habits of heart (a commitment to reflective practice). Many of the effective leadership programs in existence for college and university leaders attempt to integrate these three critical themes (Gigliotti, under review; Ruben, De Lisi, \& Gigliotti, 2017; Andrews, 2016). Additionally, there are any number of topical themes that can be incorporated as components in higher education leadership development programs, including the higher education landscape, theories of leadership, the unique nature of higher education leadership, the distinction between formal and informal leadership, communication and influence strategies, leader self-assessment, leadership styles, and the variety of tools that are most germane for academic and administrative leaders in higher education - planning, change, and the use of rubrics and metrics, for example (Ruben, De Lisi, \& Gigliotti, 2017).

In addition to the number of worthy program themes, there exist numerous leadership development philosophies, theories, and models that inform existing approaches to leadership education in colleges and universities. As we discuss elsewhere (Ruben, De Lisi, \& Gigliotti, 2017), an important step in the conceptualization, implementation, design, or adoption of any leadership development program involves a careful assessment of organizational needs, and the knowledge and competencies required for effective leadership. Furthermore, those involved with 
the design and organization of these initiatives should also assess the current culture to determine the extent to which current practices align with organizational and leadership aspirations and priorities. For a more comprehensive overview of approaches to leadership education, see Bolea and Atwater (2015), Gmelch and Buller (2015), and Van Velsor, McCauley, and Ruderman (2010).

\section{The Center for Organizational Development and Leadership (ODL) at Rutgers University}

In the pages that follow, we report on a case study of a leadership development initiative designed to systematically address the challenges of higher education leadership. The case describes the design of a conceptual, strategic, and operational framework used to guide in the creation of a portfolio of programs to address the leadership development needs of a variety of stakeholder groups at a number of levels and stages. This framework also serves as a useful theoretical model for better understanding the conceptual, strategic, and operational dimensions of leadership education across sectors. The case study that follows provides a brief overview of an integrated portfolio of leadership programs developed and coordinated through the Rutgers University Center for Organizational Development and Leadership (ODL) with support from a number of academic and administrative leaders within the institution. ODL was created in 1993 as a resource that would serve the organizational quality and leadership development needs of the Rutgers community - in particular, current and aspiring academic and administrative higher education leaders. ODL has had several reporting relationships in the university organizational chart. As of August 2016, ODL now reports directly to the Office of the Senior Vice President of Academic Affairs.

The impetus for the development of ODL was a faculty and staff committee report on administrative efficiency, which came to be referred to as The Red Tape Report (Rutgers, 1992). Issued in 1991, the report made a number of recommendations for improving the effectiveness of the institution, including the following:

1. Creating a more welcoming environment,

2. Introducing technological innovations to enhance service and efficiency,

3. Establishing and enhancing user-focused systems and processes,

4. Improving collaboration and communication, and

5. Establishing a university program for continuous improvement.

ODL was created specifically to help address these general goals.

Early on, ODL began to develop a guiding philosophy and a way of approaching the work of organizational development within the university. Fundamentally, our approach involves the following:

- identifying best practices and standards of excellence in higher education and other sectors and translating these into the language and culture of the institution;

- identifying or developing programs, models, and approaches based on expressed and/or anticipated need;

- providing ongoing support and an incubator for new initiatives, and ensuring the institutionalization of programs and core competencies necessary for their continuation; 
- promoting information sharing relative to organizational innovations and improvements throughout the university;

- encouraging and supporting the adoption and implementation of effective practices, programs, and approaches by other units; and

- serving as an organizational development research and development center for the higher education community nationally

Guided by our operating philosophy and the expressed needs of members of the university community over the years, the center has established three core program areas: organizational effectiveness, leadership advancement, and communication and change. The focus of this article is on the second of these areas, leadership advancement_-programming designed to enhance collaborative leadership knowledge and capabilities through the establishment of a suite of programs and services that directly address the many aforementioned challenges facing higher education and that encourage collaborative and innovative solutions to leading during these complex times. For more information regarding the history and current work of ODL, see http://odl.rutgers.edu/.

\section{ODL Leadership Portfolio}

The goals of ODL leadership programs are to promote organizational advancement through the development, study, and adoption of best practices; to develop increased internal capacity for leadership among our existing academic and administrative leaders; and to develop leaders of the future. In approaching the development of a leadership education portfolio, these four fundamental precepts have guided our work:

Blending knowledge and skill. Outstanding leaders possess knowledge of leadership and demonstrate an ability to translate this knowledge into practice, thereby advancing their knowledge and the effectiveness of their skills. Knowledge refers to leaders' understanding of a concept. Skill refers to leaders' effectiveness in operationalizing the knowledge they possess and their strategic ability to effectively act on this information (Ruben, 2012). Leadership issues may arise because of the gap that often exists between theory and practice-otherwise known as the knowing-doing gap (Pfeffer \& Sutton, 2000). Competency-based approaches to leadership focus on the ability of successful leaders to acquire a portfolio of knowledge and skills that they are able to apply strategically in a particular context or situation. As noted in the next precept, we believe that some leadership competencies are position-specific, but many others are crosscutting and generic (Ruben, 2012).

Integrating vertical and horizontal competencies. A vertical approach to leadership education emphasizes the positional competencies - the technical and disciplinary knowledge and skills that are unique to a particular industry, field, role, or position. A horizontal approach emphasizes cross-cutting leadership competencies that transcend specific settings - the personal, organizational, communication, and analytic competencies that have increasingly been recognized as essential for outstanding leadership across multiple contexts (Ruben, 2012, Ruben, De Lisi \& Gigliotti, 2017).

It is often the case that each organizational unit and leadership role within a college or university tends to see itself as special and distinctive in many ways. And indeed, in terms of the 
specifics of a discipline or the technical expertise practiced within the department, each unit is unique. But at the same time, all such units are organizations, and as such involve a number of common components and challenges - the need for sound leadership, effective planning, programs and services that meet high standards, a clear sense of who these programs and services benefit, attention to organizational climate, a supportive and quality environment for faculty and staff, methods for monitoring effectiveness, and strategies for capturing and using information on outcomes. For a closer look at some of the common themes of excellence that all organizations share in common, see Baldrige (2016) and Ruben (2016).

Building on the disciplinary, technical, and positional competencies of faculty, staff, and graduate and medical students, ODL programs focus on critical cross-cutting leadership competencies necessary to address the many challenges facing higher education. An illustration of these cross-cutting competencies can be found in Figure 1. As offered elsewhere (Ruben \& Gigliotti, under review), these cross-cutting competencies are increasingly essential. These competencies are foundational to our ODL leadership curriculum, and they include those skills necessary for communicating and collaborating effectively with a broad array of internal and external constituencies, dealing effectively with colleagues representing an array of interpersonal and multicultural styles, leading change, building effective teams and fostering successful teamwork, promoting innovation and translational applications from other sectors, and anticipating and dealing effectively with crisis and conflict (Ruben \& Gigliotti, under review).

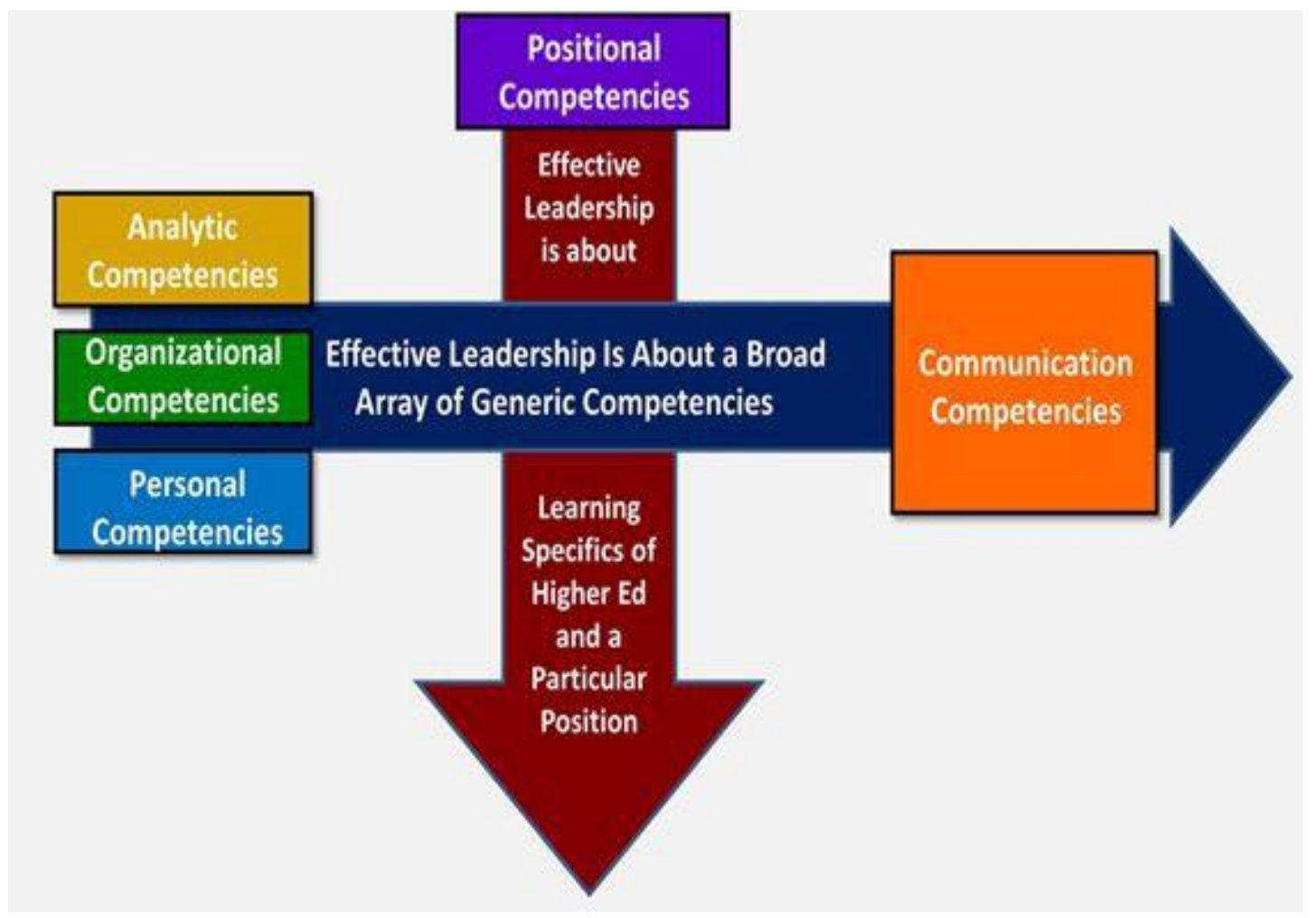

Figure 1: Cross-Cutting Leadership Competencies 
Building bridges between faculty and staff. Although faculty and staff often operate in their individual silos, we have found leadership development to be an important bridge for connecting these two groups. The challenges facing higher education demand collaborative solutions from both faculty and staff. Furthermore, the roles of faculty and staff are intimately intertwined in relation to leadership knowledge and skill. Some examples where collaboration between the two groups is critical might include project-based opportunities for collaboration, planning, and budgeting. Through formal and informal opportunities for leadership development, both faculty and staff can gain a deeper understanding of and appreciation for the roles, responsibilities, and priorities of the other.

Fostering collaborative engagement and sponsorship. Few programmatic themes are mentioned more frequently than leadership in discussions of the present and future needs of higher education. Not surprisingly then, programming efforts may spring up in a great many locations and levels within a college or university. This growing popularity validates the importance of the theme, and yet it also leads to potential confusion, waste, and duplication of resources in program development efforts. A final critical precept worth noting is the importance of fostering collaborative engagement and sponsorship across multiple levels of the institution in pursuit of advancing leadership education.

With these four precepts in mind, our plan was to develop a portfolio of integrated leadership programs with a common core. As noted earlier, an integrated and aligned leadership education curriculum has benefits in terms of internal integrity and consistency, along with effectiveness and efficiency of implementation. This article contributes to the ongoing literature on leadership development in higher education based on these four aforementioned concepts. Particularly given the challenges facing colleges and universities across the globe, this likely is an area that will continue to receive increasing attention from both scholars and practitioners (Andrews, 2016).

\section{Levels of Programmatic Integration: Conceptual, Strategic, and Operational}

Conceptual Dimension: ODL Leadership Curriculum. At the conceptual level, the ODL leadership curriculum includes a portfolio of programs and an array of modules grounded in relevant communication, leadership, and organizational theory. This curriculum focuses on the development of cross-cutting leadership concepts, competencies, and tools needed to advance one's department, program, or school; and to be able to guide colleagues in creating and implementing a shared and compelling vision for the future.

In order to create an integrated conceptual foundation for a number of leadership programs, collaboration, support, and resource sharing among various units and individuals are critical. The modules listed below in Figure 2 draw upon diverse leadership theories, philosophies, and models - selected and created for their particular relevance to higher education and academic medicine and health (Ruben, De Lisi, \& Gigliotti, 2017). These modules are comprehensive in scope and are designed to meet the needs of academic and administrative leaders. Each module contains supplemental readings and a series of case studies that can be customized based on the goals of the specific unit, department, or leadership group. The content in these modules - both theoretical and applied in focus - is grounded in scholarly literature, 
informed by relevant leadership, higher education, and communication theory, and made accessible for both academic and administrative leaders. As depicted below, many of the modules address an array of cross-cutting leadership topics, strategies, and tools that could extend beyond the domain of higher education, along with a number of "vertical," higher education-specific modules listed in the second section.

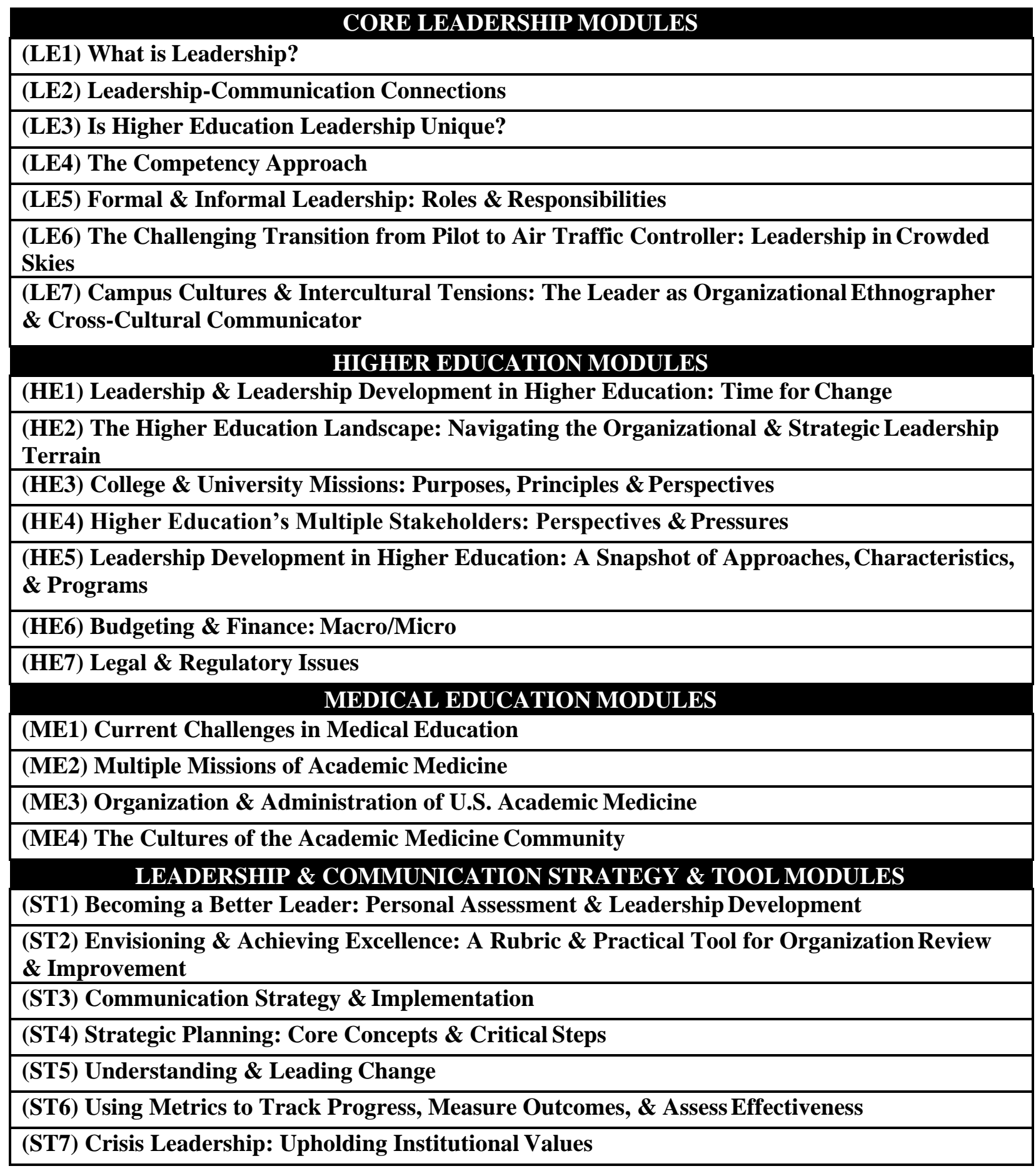

Figure 2: ODL Leadership Modules 
Strategic Dimension: Our Approach to Leadership Education. Although the ODL approach to leadership development varies to a certain extent based on the needs and goals of a particular unit, there are notable areas of convergence. Based on our experience of providing leadership education to wide array of audiences across the institution, we have found a number of strategic insights regarding leadership development to be useful in developing - and sustaining - highly regarded leadership education initiatives at our institution.

- The complex and interdependent challenges facing higher education require attention from faculty and staff. Many existing approaches to training and development tend to isolate these individual groups, but we have found much success in bringing these groups together to address the cross-cutting challenges in higher education, such as our Rutgers Leadership Academy that brings together these distinct audiences. It is likely the case that solutions to existing problems will demand collaboration from both stakeholder groups.

- There seems to be no one single "correct" approach to leadership development in higher education. Individual learning preferences, coupled with the unique challenges of a unit, department, or institution, call for customized approaches to training and development that best meet one's specific needs.

- Assessment remains a critical commitment for those involved in the design and implementation of leadership education initiatives (Gigliotti, 2015a; Owen, 2011). The assessment process is important for not only justifying the use of resources for leadership education, but also as a way of improving the quality and effectiveness of these programs. We use multiple approaches to program evaluation and assessment, including preand post-tests of program participants, session-based and program-based evaluations, and in some instances, 360 inventories and more extensive research-based interviews with those involved in our leadership programs.

- No one workshop, multi-day program, or book can be expected to have a transformative effect on a person's leadership capability (Ruben, De Lisi, \& Gigliotti, 2017). As Gmelch and Buller (2015) suggest, "if we assume that it takes ten to twenty years for a highly intelligent person to become an expert in an academic discipline, why do we assume that we can train academic leaders in a three-day workshop"? (p. 8). It is certainly the case that individual programs and leadership resources can introduce learners to new concepts, skills, and strategies, but leadership development is better understood to be an ongoing process that evolves over time and with practice.

- As noted earlier, the culture of a unit, department, or organization provides a natural laboratory for leadership learning - for better and for worse. The culture provides a powerful set of expectations as it relates to defining and socializing leadership behavior. To the extent that the culture and the customary behaviors of leaders are exemplary of positive ideals of organizational and leadership effectiveness, the task of leadership development programs is primarily to reinforce those values and behaviors. Where organizational practices and leadership behaviors and practices are less than fully exemplary of ideal practices, or where organizational or leadership change are motivational goals in leadership development efforts, the challenges are substantially more complex. In these instances, leadership preparation initiatives must strive to address, overcome, or circumvent the undesirable consequences of the natural socialization processes that occur each day throughout an organization, and which create impediments to meaningful organizational advancement and change-breaking out of or creating an alternative to the dominant culture (Ruben, De Lisi, \& Gigliotti, 2017). 
- Many of the same factors involved in the organization, delivery, and assessment of undergraduate student leadership initiatives and leadership education initiatives in other sectors is relevant to training and development in higher education. For example, based on experiences in ODL, we have found the use of pre-tests/post-tests, differentiated instructional methods, and experiential learning activities to be critical components of our leadership efforts. For example, rather than simply learn about the concepts of change leadership, Fellows in the Rutgers Leadership Academy program have an opportunity to learn about the change process through an experiential visit to the newly created New Jersey Institute for Food Nutrition and Health, where they learn first-hand about the leadership and organizational challenges from those who designed, implemented, and currently lead the Institute. They also have an opportunity to practice these change leadership behaviors through the completion of a year-long capstone project. In addition to learning about the political dynamics of higher education leadership, Fellows in the PreDoctoral Leadership Development Institute learn directly from policy makers and influential figures in a forum in Washington, DC. Finally, going beyond the knowledge acquisition that comes from participation in didactic sessions, Fellows in the Leadership in Academic Healthcare program can pursue a formal distinction on their diploma by participating in two field experiences under the mentorship of senior leaders in academic medicine and through the completion a field-based project.

- Collaboration is critical to the success of leadership development programs (Gigliotti, $2015 \mathrm{a} ; 2015 \mathrm{~b}$ ). As acknowledged in the footnote descriptions of our individual programs, these initiatives are collaborative by nature and their success hinges very much on the support and buy-in of our many campus partners. ODL colleagues and graduate coordinators assist with the administration of specific programs, and our collaboration with other units remains mutually beneficial.

\section{Operational Dimension: Collaborative Leadership Development Programs.}

Building upon the aforementioned leadership curriculum and a strategic approach to leadership education, ODL offers a suite of collaborative programs for effective leadership development in higher education. The intended audience varies based on program, as do the learning outcomes, delivery methods, and methods of assessment for each program. At an operational level, these programs seek to improve the leadership capacity of faculty, staff, and graduate students across the institution. At the same time, the involvement of current leaders as sponsors, mentors, and presenters broadens dialogue regarding organizational and leadership ideals and practices among all who are involved in any capacity with the programs. Indeed, broadening conversations and reflections about effective leadership practices across the campus may be one of the greatest indirect benefits of engaged leadership development programs such as these. Below is graphic illustration of the leadership programs in Figure 3, along with a brief overview of each of the programs. 


\title{
The Rutgers Center for Organizational Development and Leadership
}

\section{LEADERSHIP PORTFOLIO}
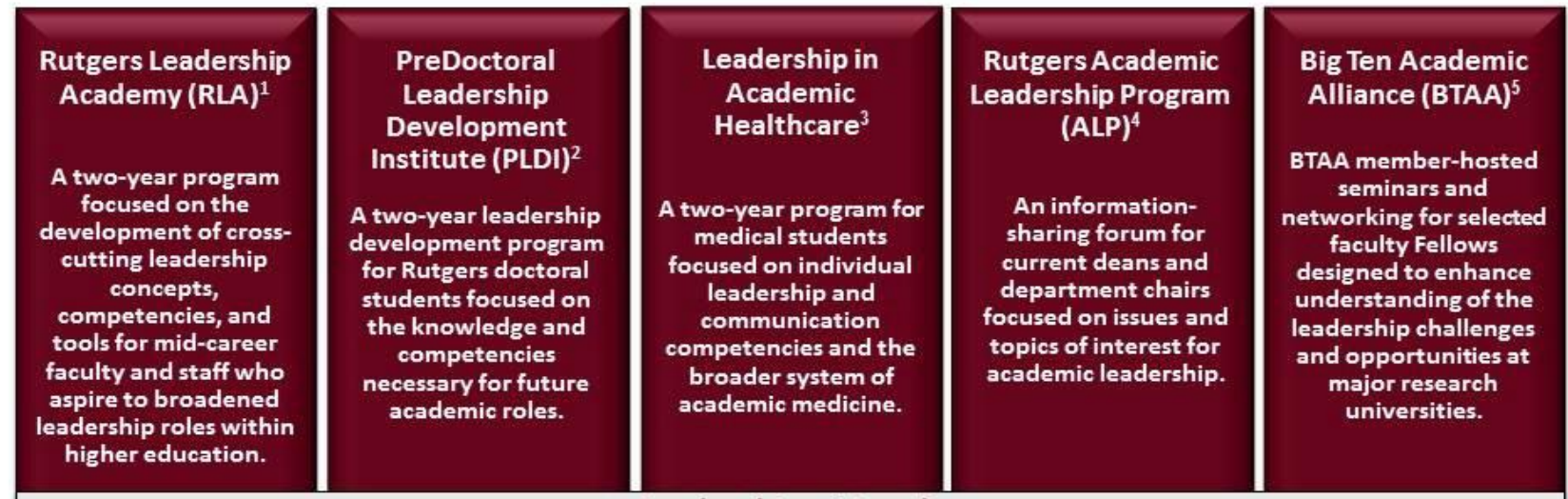

Leadership at Lunch

"Brown bag" lunch seminars that address a variety of skills, topics, and tools of potential use to any faculty, staff, and students with an interest in higher education leadership.

For more information, contact us at: center@odl.rutgers.edu * 848-932-3963 * www.od1.rutgers.edu

\begin{abstract}
ISponsored bythe Office of the Chancellor, Rutgers-NB. Mid-career faculty and staff within units or schools that report to the Chancellor of Rutgers-New Brunswick or the Chancellor of Rutgers Biomedical and Health Sciences are eligble to be nominated.

${ }^{2}$ Sponsored by ODL; the Graduate School-NB; Office of the Chancellor, Rutgers-NB; Office of the Senior Vice President for Academic Affairs, the Graduate School of Education, and the School of Communication and Information.

${ }^{3}$ Offered by Robert Wood Johnson School of Medicine in collabaration with ODL

${ }^{4}$ Sponsored by ODL; Office of the Chancellor, Rutgers-NB; Office of Senior Vice President for Academic Affairs, the Graduate School-NB, University Human Resources; and the School of Communicationand Information.

'Sponsored bythe Office of the Chancellor, Rutgers-NB in collaboration with ODL
\end{abstract}

Figure 3: ODL Leadership Profile

Rutgers Leadership Academy (RLA). Part of the New Brunswick Strategic Plan, the Rutgers Leadership Academy (RLA) focuses on the development of cross-cutting leadership concepts, competencies, and tools to enhance professional capabilities for those in academic, professional and administrative leadership roles. RLA is a two-year program for mid-career faculty and staff who aspire to broadened leadership roles within their units, the University and/or higher education, more generally. Individuals nominated as Fellows must be members of units or schools which report to the Chancellor in New Brunswick or the Chancellor of Rutgers Biomedical Health Sciences. The program is open to those with or without experience serving in leadership positions in higher education. The Academy is offered by ODL with sponsorship from the Office of the Chancellor, Rutgers-New Brunswick.

The RLA program consists of 16 three-hour sessions over four semesters. Topics include, but are not limited to, the following:

- The Higher Education Landscape

- Multiple Missions of the Academy

- What is Leadership?

- What Makes Higher Ed Leadership Unique?

- Formal \& Informal Leadership 
- Personal Assessment \& Leadership Development

- Planning, Communication \& Change

As a result of participating in the RLA, Fellows will be able to:

- Gain familiarity with contemporary challenges facing academic and administrative leaders

- Deepen understanding of fundamental perspectives and concepts of leadership as they apply in higher education

- Enhance personal and professional leadership competencies

- Advance Rutgers and one's leadership capabilities by leading a field-based project from conception through completion

- Increase understanding of important dimensions of higher education administration, including organizational structure and mission, governance, finance and budgeting, legal and regulatory issues, diversity, and ethics

As a component of the Program, Fellows lead a field-based project from conception through completion. All projects should address a significant area of need, and should aim to strengthen and advance the university. These projects are intended to provide a context for applying and furthering the development of leadership competencies, while contributing meaningfully to significant needs of the institution. Referring back to the horizontal and vertical approach to leadership education noted earlier, these projects allow Fellows to apply their cross-cutting knowledge and skill within a vertical context. The exercise is a useful one for thinking through the unique challenges of leading initiatives within the unique context of higher education.

PreDoctoral Leadership Development Institute (PLDI). Each year, the PreDoctoral Leadership Development Institute (PLDI) welcomes a select group of Rutgers doctoral students from a broad array of disciplines to its two-year program. Traditional discipline-based doctoral education is devoted to preparing students for careers in scholarship and teaching, but often these future faculty members complete their degree with little preparation for academic and administrative leadership roles in their institutions. A critical need exists for individuals who also understand the structure and dynamics of colleges and universities, know the challenges these institutions face, and possess the interpersonal and organizational knowledge, competencies and aspirations to provide effective and ethical leadership in addressing the critical issues confronting higher education (Gigliotti, et al., 2016).

While it may be years before new doctoral graduates move into formal leadership roles, leadership expertise is needed immediately for working in teams and workgroups, pursuing research funding and support, participating in mentoring and advising relationships with students and colleagues, and for assuming the many informal leadership roles at their institutions. Through participation in the Institute, students can become more effective members of the academic community, more capable leaders and collaborators within their disciplines and their future places of employment, and for these reasons, more marketable and well-prepared for influential careers. PLDI is sponsored by ODL; the Graduate School-New Brunswick; Office of the Chancellor, Rutgers-New Brunswick; Office of the Senior Vice President for Academic Affairs, the Graduate School of Education, and the School of Communication and Information. 
As a result of participating in PLDI, Fellows will be able to:

- Demonstrate familiarity with contemporary challenges and issues facing higher education and higher education leaders;

- Demonstrate a developing understanding of fundamental perspectives and concepts of leadership as they apply in higher education settings;

- Identify the multiple factors, constituencies, perspectives, policies and practices that influence decision-making in higher education;

- Identify and explicate important dimensions of higher education and administration in colleges and universities, including mission, organizational structure, governance, finance, legal and regulatory issues, diversity, and ethics;

- Demonstrate an understanding of leadership styles and strategies and their impact;

- Demonstrate an analytic/critical perspective relative to leadership perspectives and concepts;

- Assess group and organizational leadership practices and situations

- Demonstrate enhanced personal and professional leadership competence; and

- Demonstrate the skills and commitment necessary for assessing one's own leadership performance.

Leadership in Academic Healthcare. The Leadership in Academic Healthcare program, co-sponsored by the Robert Wood Johnson Medical School, is a two-year program for medical students that focuses on individual leadership and communication competencies and the broader system of academic medicine. The program, offered by the Robert Wood Johnson School of Medicine in collaboration with ODL, provides an opportunity for motivated medical students to enrich their educational experience by participating in an intense experiential learning activity, along with the opportunity to develop collaborative skills in the planning, implementation, participation, and dissemination of a field project in the realm of academic medicine administration. Additionally, this initiative highlights the horizontal and vertical competencies needed to be an effective leader in academic medicine within the broader context of higher education.

The program consists of two distinct tracks:

Noncredit Elective: Optional participation in 16 didactic sessions on a variety of topics related to leadership, communication, and academic healthcare.

Distinction in Leadership: In addition to participating in the 16 required didactic sessions, students who choose to pursue the formal Distinction may also complete two field experiences under the mentorship of senior leaders in academic medicine, along with a field-based project that will be reviewed by the Distinction in Leadership Committee and will be presented at an annual symposium.

As a result of participating in the Leadership in Academic Healthcare program, participants will be able to:

- Gain familiarity with contemporary challenges facing academic medicine and higher education leaders.

- Deepen understanding of fundamental perspectives and concepts of leadership.

- Enhance personal and professional leadership competencies.

- Advance professional development by leading a field-based project from conception through completion. 
- Increase understanding of important dimensions of higher education administration, including organizational structure and mission, governance, finance and budgeting, legal and regulatory issues, diversity, and ethics.

As noted earlier, each program addresses general organizational and leadership theory and practice issues, and also includes a focus on the current landscape within a particular discipline, field, or domain. Thus, where the focus for some groups would be on general higher education issues and challenges, programs for medical students and groups would shift the emphasis to the current state and future challenges in clinical medicine.

Rutgers Academic Leadership Program (ALP). The Rutgers Academic Leadership Program (ALP) provides a forum for disseminating information on policies and practices, addressing theoretical and practical problems of academic leadership, sharing effective practices across disciplines, and creating a collaborative network of administrators and faculty members charged with providing academic leadership for the institution. Components of the program include an orientation for new deans and chairs, a breakfast discussion series, and an academic leadership website. Rutgers ALP is sponsored by ODL; Office of the Chancellor, Rutgers-NB; Office of Senior Vice President for Academic Affairs; the Graduate School-NB; University Human Resources; and the School of Communication and Information.

Big Ten Academic Alliance Leadership Programs. Rutgers-New Brunswick is a member of the Big Ten Academic Alliance (BTAA) - formerly named the Committee on Institutional Cooperation (CIC). Through the Office of the Chancellor, Rutgers-New Brunswick, the university is actively engaged with the BTAA in areas related to leadership development, among others, and our affiliation provides a variety of opportunities for Rutgers faculty and academic administrators, including the Academic Leadership Program and Departmental Executive Officers Seminars (Big Ten Academic Alliance, 2016).

Academic Leadership Program. Established in 1989, this intensive BTAA leadership initiative develops the leadership and managerial skills of faculty who have demonstrated exceptional ability and academic promise. Many of the programs' nearly 1000 Fellows have gone on to serve with distinction as college presidents, provosts, and deans. The Leadership Program consists of three seminars hosted by different Big Ten universities (http://www.btaa.org/projects/leadership/alp/introduction). In addition, Academic Leadership Program Fellows often participate in on-campus activities throughout the academic year at their home institution. The program is specifically oriented to address the challenges of academic administration at major research universities.

Departmental Executive Officers Seminars. The Departmental Executive Officers (DEO) Seminars include a variety of activities designed to facilitate informationand expertise-sharing among department heads from across Big Ten institutions relative to departmental leadership issues. Each year, Big Ten member institutions have the opportunity to select up to four department chairs to participate in the Seminar. Each year approximately 65 department heads and chairs from Big Ten universities come together for a unique leadership development seminar. Topics at this three-day event range from 
conflict resolution and time management to faculty development, performance reviews, and group problem solving.

Selected Fellows from Rutgers are invited to attend various ODL leadership workshops and lectures throughout the year. Additionally, under the guidance of ODL, Fellows work collaboratively on institution-wide projects throughout their year-long fellowship.

Leadership at Lunch Seminar. These "brown bag" lunch seminars address a variety of skills, topics, and tools of relevance to current and aspiring leaders with an interest in higher education leadership. ODL, along with other units from across campus, offer two lunch-time sessions per semester and a Higher Education Leadership Lecture by a national higher education leader to individuals of existing ODL leadership programs and others on a space available basis. Similar to our other leadership initiatives, these lunches integrate both the horizontal and vertical competencies needed to effectively lead in higher education. The topics for the lunches reflect contemporary issues in higher education, and they are directly informed by the existing challenges, issues, and circumstances impacting our specific institution.

\section{Conclusion}

This case study highlights the value of using a theoretical framework for approaching leadership education in a systematic and intentional manner. In particular, there is value in addressing both the general (horizontal) and specific (vertical) knowledge and skills needed for effective leadership in higher education. Additionally, the leadership portfolio presented in this case reflects the importance of blending knowledge and skill, building bridges between faculty and staff, and fostering collaborative engagement and sponsorship. The ODL leadership modules are organized in an integrated way in order to make the core themes, knowledge, and skills accessible and available across programs and audiences. The framework considers the intersecting conceptual, operational, and strategic dimensions associated with leadership education, resulting in a portfolio of collaborative leadership programs that leverages multiple interests, programs, and audiences interested in leadership and that creates value-adding collaborative relationships. Future research can further explore the characteristics of and connections between the conceptual, operational, and strategic dimensions of leadership education both within higher education and across sectors. We have become committed to the merits - both in terms of effectiveness and efficiency — of an integrated portfolio of leadership programs. We have found this model to be useful given the unique culture and challenges of our institution - and it is our hope that this framework is instructive for others who are involved with the design and delivery of leadership education initiatives for existing and aspiring leaders in higher education in response to many of the existing challenges and opportunities facing colleges and universities. 


\section{References}

Altbach, P., \& Davis, T., (1999). Global challenge and national response: Notes for an international dialogue on higher education, Chapter 1, pp. 3-10. Higher Education in the 21st Century: Global Challenge and National Response, IIE Research Report No. 29. The Institute of International Education.

Andrews, M. (2016, May 30). Teaching leadership. Inside Higher Ed. Retrieved June 13, 2016 from https://www.insidehighered.com/blogs/stratedgy/teachingleadership?utm_source=Inside+Higher+Ed\&utm_campaign=df5eb913b9-

DNU20160531\&utm_medium=email\&utm_term=0_1fcbc04421-df5eb913b9-198447317

Association for Talent Development (2015). 2015 State of the Industry. Retrieved December 8, 2015, from https://www.td.org/Publications/Research-Reports/2015/2015-State-of-theIndustry

Baldrige National Quality Program. (2016). http://www.nist.gov/baldrige/.

Barge, J. K., \& Fairhurst, G. (2008). Living leadership: A systemic constructionist approach. Leadership Quarterly, 4(3), 227-251.

Bass, B. M. (1990). Bass \& Stogdill's handbook of leadership: Theory, research, \& managerial applications (3rd ed.). New York: The Free Press.

Big Ten Academic Alliance. (2016). Retrieved October 11, 2016 from http://www.btaa.org/home

Bolea, A., \& Atwater, L. (2015). Applied leadership development: Nine elements of leadership mastery. New York: Routledge.

Bolman, L. G., \& Gallos, J. V. (2011). Reframing academic leadership. San Francisco: JosseyBass.

Buller, J. L. (2014). Change leadership in higher education: A practical guide to academic transformation. San Francisco: Jossey-Bass.

Collins, J. (2001). Good to great. Why some companies make the leap ... and others don't. New York: Harper Business.

Fairhurst, G. T. (2007). Discursive leadership: In conversation with leadership psychology. Thousand Oaks, CA: Sage.

Fairhurst, G. T., \& Connaughton, S. L. (2014a). Leadership: A communicative perspective. Leadership, 10(7), 7-35. 
Fairhurst, G. T., \& Connaughton, S. L. (2014b). Leadership communication. In L. L. Putnam \& D. K. Mumby (Eds.), The SAGE handbook of organizational communication: Advances in theory, research, and method (pp. 401-423). Thousand Oaks, CA: Sage.

Fairhurst, G. T., \&Sarr, R. (1996). The art of framing: Managing the language of leadership. San Francisco: Jossey-Bass.

Gigliotti, R. A. (2015a). Cultivating alumni engagement in undergraduate leadership education: The Villanova University Student Leadership Forum. Journal of Leadership Education, 14(3), 152-158.

Gigliotti, R. A. (2015b). "Streams of influence" in student affairs: A renewed emphasis on leadership education. Journal of Student Affairs Research and Practice, 52(4), 427-439.

Gigliotti, R. A., Agnew, B., Goldthwaite, C., Sahay, S., Dwyer, M., \& Ruben, B. D. (2016). Scholar in training; leader in training: The Rutgers University PreDoctoral Leadership Development Institute. In P. Blessinger \& D. Stockley (Eds.), Emerging directions in doctoral education (pp. 39-59). Bingley, UK: Emerald Group Publishing.

Gigliotti, R. A. (forthcoming). An exploratory study of academic leadership education within the Association of American Universities. Journal of Applied Research in Higher Education.

Gmelch, W. H., \& Buller, J. L. (2015). Building academic leadership capacity: A guide to best practices. San Francisco: Jossey-Bass.

Grint, K. (2000). The arts of leadership. Oxford: Oxford University Press.

March, J. G., \& Weil, T. (2005). On leaderhip. Malden, MA: Blackwell.

Northouse, P. G. (2015). Leadership: Theory and practice (7th ed.). Thousand Oaks, CA: Sage.

Owen, J. E. (2011). Assessment and evaluation. In S. R. Komives, J. P. Dugan, J. E. Owen, C. Slack, \& W. Wagner (Eds.), The handbook for student leadership development (2nd ed., pp.177-202). San Francisco, CA: Jossey-Bass.

Ruben, B. D. (2004). Pursuing excellence in higher education: Eight fundamental challenges San Francisco: Jossey-Bass.

Ruben, B. D. (2012). What leaders need to know and do: A leadership competencies scorecard. (2nd ed). Washington, DC: National Association of College and University Business Officers.

Ruben, B. D. (2016a). Excellence in higher education: A framework for the design, assessment, and continued improvement of institutions, departments, and programs (8th ed.). Sterling, VA: Stylus. 
Ruben, B. D., De Lisi, R., \& Gigliotti, R. A. (2017). A guide for leaders in higher education: Core concepts, competencies, and tools. Sterling, VA: Stylus.

Ruben, B. D. \& Gigliotti, R. A. (2016). Leadership as social influence: An expanded view of leadership communication theory and practice. Journal of Leadership and Organizational Studies.

Ruben, B. D. \& Gigliotti, R. A. (under review). Are higher education institutions and their leadership needs unique? The vertical versus horizontal perspective.

Velsor, E. V., McCauley, C. D., \&Ruderman, M. N. (2010). The center for creative leadership handbook of leadership development. San Francisco: Jossey-Bass.

Witherspoon, P. D. (1997). Communicating leadership: An organizational perspective. Boston: Allyn \& Bacon.

\section{Author Biographies}

Ralph A. Gigliotti is assistant director for the Center for Organizational Development \& Leadership at Rutgers University, where he is also a doctoral candidate and part-time lecturer in Communication. His research interests explore the intersection of organizational communication, leadership, and crisis communication, particularly in the context of higher education.

Brent D. Ruben, Ph.D., is a distinguished professor, and executive director of the Center for Organizational Development and Leadership at Rutgers University. He is also a member of the faculties of the Rutgers Ph.D. Program in Higher Education and the Robert Wood Johnson School of Medicine. Brent's academic interests include human communication, organizational leadership, planning, assessment, and change. 